\title{
Living with extremes: the dark side of global climate change
}

\author{
Thomas Abeli • Anne Jäkäläniemi • \\ Rodolfo Gentili
}

Published online: 29 June 2014

(C) Springer Science+Business Media Dordrecht 2014

We are pleased to announce a new special issue of Plant Ecology on extreme weather events.

The new report of IPCC (2013) predicts remarkable increase in global mean air temperatures. Depending on the scenarios, the best estimates of temperature increase range from 1.8 and $4.0^{\circ} \mathrm{C}$ by 2100 . Climate change may generally act in two ways: gradual warming will affect plants and vegetation over short (decades), medium (centuries), and long (millennia and over) timescales, with some effects already evident, including upward altitudinal plant migrations in mountain regions, species turnover, range shifts and changes in vegetation patterns (Dullinger et al. 2012). In many cases, increased mean temperature corresponds to increased variability, leading to more extreme temperatures, and increased heat energy in the atmosphere, which promotes the development and intensity of extreme weather (Easterling et al. 2000). Consequently, climate change is characterized also by

T. Abeli ( $\square)$

Department of Earth and Environmental Sciences, University of Pavia, Via S. Epifanio 14, 27100 Pavia, Italy e-mail: thomas.abeli@unipv.it

\footnotetext{
A. Jäkäläniemi

Oulanka Research Station, Thule Institute, University of Oulu, Oulu, Finland

R. Gentili

Department of Earth and Environmental Sciences, University of Milano-Bicocca, Milan, Italy
}

unpredictable extreme weather events (EWEs) such as heat waves, extreme droughts, heavy rains, storms and their associated effects like increased frequency of fires, floods, etc. The occurrence of EWEs has been more common in the last 20 years, as a direct effect of increased temperatures (Easterling et al. 2000). EWEs may adversely affect natural ecosystems, crop productivity and human health, and facilitate biological invasions (Ciais et al. 2005). The recent examples of EWEs include: the extremely hot summer in Southern Europe in 2003, when the thermometer marked $40{ }^{\circ} \mathrm{C}$ for several consecutive days, and the exceptional flooding of Lake Eyre South (South Australia) in 2011. However, our understanding of EWEs effects on plant life and vegetation remains poor. While gradual rising of temperature allows species to adapt or at least to acclimate to the changing environment, extreme weather works like a stochastic event, with rapid and unpredictable effect on plant fitness and survival (Niu et al. 2014).

The study of EWEs is in its infancy in the scientific literature, and it is a promising and pertinent research field for the future. To date, most studies of the effects of EWEs have been published in special issues of plant science journals, demonstrating that special issues play the special role in promoting research in this field and summarizing the current state of knowledge.

This special issue of Plant Ecology will advance our ecological understanding of direct and indirect effects of EWEs on plants, with attention to a broad 
range of aspects including evolutionary perspectives, ecology, reproductive biology, physiology and research methodology. By reporting on, and synthesizing information from an increasing number of empirical case studies, we seek to identify general patterns of plant responses to such events.

This special issue on climate extremes starts by the review of the most recent studies on the effect of extreme events on plants. In their novel synthesis, Orsenigo et al. (2014) report on the quantitative analysis of the effect of heat waves, droughts, frosts, advanced or delayed snow melting, and heavy rainfall on several plant performance traits. The authors highlight that the plant response to extreme events of different types and magnitudes is very specific, and conclude that the number of study cases is still too small to reveal general patterns.

The article by Vincenzi and Piotti (2014) presents a modeling approach to estimate the probability of local population extinction of Pinus pinaster due to increased frequency of fire in relation to serotiny. They observed an increasing probability of population extinction with increasing frequency of fire, and identified the role of serotiny in mitigating such extinction risk. However, the evolution of serotiny with increasing fire frequency was less clear. The next seven articles are all case studies and deal with different types of extreme events, with heat waves and droughts being the most common.

Forner et al. (2014) highlight how different species have varying responses to extreme events. The authors tested the response of Pinus nigra and Quercus faginea to drought, in Spain. Pinus was able to rapidly recover from drought stress, while Quercus showed difficulties in its recovery. This may indicate the different competitive relationships between the species, when exposed to EWEs.

Different sensitivity to drought is predicted to change competitive abilities for dominant grass species, which may have consequences at the ecosystem level. Hoover et al. (2014) compared physiology and productivity of two $\mathrm{C}_{4}$ grasses in North America (Andropogon gerardii and Sorghastrum nutans) in relation to drought and heat waves of varying intensities. They concluded that although heat stress may have some effects, drought was the major driver of plant stress.

Bauweraerts et al. (2014) show that plants, especially in their early life stages, may acclimate to
EWEs, like heat waves, allowing seedlings to survive during recurrent events. The seedlings of Quercus rubra were able to modulate their stomatal conductance in order to avoid water loss during extremely hot weather. However, at high $\mathrm{CO}_{2}$ concentration the acclimation potential may be reduced. Although extreme events can exert strong selective pressures on plants and promote adaptation to a harsher environment, they can also push populations to local extinctions.

Marcante et al. (2014) studied the direct effect of heat stress on plants associated with heat waves. They examined the heat tolerance of several high altitude (alpine) species growing at the glacier forelands in the Alps, one of the most sensitive habitats to climate change. They included the heat wave responses of seedlings, which are considered the most sensitive plant life stage and a thermometer of mother plant fitness. They found that plant tolerance to heat stress decreases from seeds to seedlings, which explains the high seedling mortality in the glacier foreland when seeds germinate in unprotected microsites.

Petraglia et al. (2014) studied experimentally how different plant species responded to earlier snowmelt in alpine communities in central Alps. It advanced flowering for some species, but had no effect on mortality. However, there was much variation among species.

Although, extreme weather fluctuations can also be EWEs, very little attempt has been made to study extreme fluctuations in temperature, rainfall, and frost events. Miranda et al. (2014), present a remarkable experiment on the effect of a changed rainfall pattern on the Mediterranean shrub Phagnalon saxatile. Low watering frequency stimulated the species reproductive performance, which may in turn increase fitness under reduced rainfall patterns.

Besides observational and experimental works, a major challenge for the study of EWEs is to develop methodological and simulation techniques in order to understand better these stochastic phenomena. Longepierre et al. (2014) provide recommendations regarding rainfall interception experiments and drought simulations in the field. They found that, although rainfall interception experiments effectively increase drought stress for plants in a Mediterranean shrubland, water dynamics of deep soil layers may reduce the actual water deficit in experimental plots. However, the impact could vary among species with different rooting patterns (shallow vs. deep). 


\section{Conclusions}

On-going climate change will inevitably lead to changes in ecosystems, ranging from gradual to catastrophic in type. Increasingly, frequent EWEs will likely lead to the most rapid and significant changes in vegetation dynamics and structure. At one end of the spectrum, there are widely distributed and long lasting EWEs, which remove whole populations and divert successions. If increased in frequency (and intensity), these harsh events will lead to increases in migrant/ pioneer species and benefit species with high dispersal and colonization capacity. It then follows that the presence of late successional stages of vegetation and of species characterized by low rates of recruitment and spread abilities, may be disadvantaged and then decrease. Alternatively, in an evolutionary sense, EWEs might increase selection pressure with new combinations of traits and species arising through sexual reproduction.

The articles in this issue highlight the varying responses of different species to EWEs. Under changing climate we must ask if changes are too rapid for the adaptation or migration capability of species? And, will species with narrow habitat requirements be particularly prone to extinction? In this context, the scale of EWEs is relevant, since small scale EWEs may only affect parts of a population, exerting selective pressure and driving increased variability. Some of the articles here report high variability among individuals, which may also correspond to genetic variability. However, whether such genetic differences among individuals are enough to insulate species against change remains uncertain.

\section{References}

Bauweraerts I, Ameye M, Wertin TM, McGuire MA, Teskey RO, Steppe K (2014) Acclimation effects of heat waves and elevated $\left[\mathrm{CO}_{2}\right]$ on gas exchange and chlorophyll fluorescence of northern red oak (Quercus rubra L.) seedlings. Plant Ecol. doi:10.1007/s11258-014-0352-9

Ciais P, Reichstein M, Viovy N et al (2005) Europe-wide reduction in primary productivity caused by the heat and drought in 2003. Science 437:529-533

Dullinger S, Gattringer A, Thuiller W et al (2012) Extinction debt of high-mountain plants under twenty-first-century climate change. Nat Clim Chang 2:619-622

Easterling DR, Meehl GA, Parmesan C, Changnon SA, Karl TR, Mearns LO (2000) Climate extremes: observations, modeling, and impacts. Science 289:2068-2074

Forner A, Aranda I, Granier A, Valladares F (2014) Differential impact of the most extreme drought event over the last half century on growth and sap flow in two coexisting Mediterranean trees. Plant Ecol. doi:10.1007/s11258-014-0351$\mathrm{x}$

Hoover DL, Knapp AK, Smith MD (2014) Contrasting sensitivities of two dominant $\mathrm{C} 4$ grasses to heat waves and drought. Plant Ecol. doi:10.1007/s11258-014-0345-8

IPCC (2013) Climate change 2013: the physical science basis. Contribution of working group I to the fifth assessment report of the intergovernmental panel on climate change, Cambridge University Press, Cambridge

Longepierre D, Mouillot F, Ouelhazi B, Ourcival JM, Rocheteau A, Degueldre D, Rejeb MN (2014) True water constraint under a rainfall interception experiment in a Mediterranean shrubland (northern Tunisia): confronting discrete measurements with a plant-soil water budget model. Plant Ecol. doi:10.1007/s11258-014-0349-4

Marcante S, Erschbamer B, Buchner O, Neuner G (2014) Heat tolerance of early developmental stages of glacier foreland species in the growth chamber and in the field. Plant Ecol. doi:10.1007/s11258-014-0361-8

Miranda JD, Jorquera MJ, Pugnaire FI (2014) Phenological and reproductive responses of a semiarid shrub to pulsed watering. Plant Ecol. doi:10.1007/s11258-014-0354-7

Niu S, Luo Y, Li D, Cao S, Xia J, Li J, Smith MD (2014) Plant growth and mortality under climatic extremes: an overview. Environ Exp Bot 98:13-19

Orsenigo S, Mondoni A, Rossi G, Abeli T (2014) Some like it hot and some like it cold, but not too much: plant responses to climate extremes. Plant Ecol. doi:10.1007/s11258-0140363-6

Petraglia A, Carbognani M, Petit Bon M, Delnevo N, Chiari G, Tomaselli M (2014) Responses of flowering phenology of snowbed plants to an experimentally imposed extreme advanced snowmelt. Plant Ecol. doi:10.1007/s11258-0140368-1

Vincenzi S, Piotti A (2014) Evolution of serotiny in maritime pine (Pinus pinaster) in the light of increasing frequency of fires. Ecol. doi:10.1007/s11258-014-0342-y 